\title{
In Situ Epoxidation of Sesame Seed Oil for Synthesis of a Bio-based Resin
}

\author{
Kenechi Nwosu-Obieogu ${ }^{1 *}$, Uduma Chinweikpe Kalu ${ }^{1}$
}

\author{
${ }^{1}$ Chemical Engineering Department, Michael Okpara University of Agriculture, Umudike, NIGERIA \\ *Corresponding Author: kenenwosuobie@yahoo.com
}

Citation: Nwosu-Obieogu, K., \& Kalu, U. C. (2020). In Situ Epoxidation of Sesame Seed Oil for Synthesis of a Bio-based Resin. European Journal of Sustainable Development Research, 4(3), em0121. https://doi.org/10.29333/ejosdr/7830

\section{ARTICLE INFO}

Received: 14 Dec. 2019

Revised: 20 Feb. 2020

Accepted: 24 Feb. 2020

\begin{abstract}
This study is aimed at the modification of sesame seed oil to develop a biobased resin. Neat sesame seed oil was epoxidized via in-situ conventional method with peroxyacetic acid at $75^{\circ} \mathrm{C}$. Biobased resins were synthesized by further modifying the epoxidised oil with acrylic and methacrylic acid respectively at $90^{\circ} \mathrm{C}$ in the presence of hydroquinone. Conversion rate of $76.54 \%$ and high oxirane content of $3.83 \%$ at a reaction time of 7 hours was achieved for the epoxidation process. FT-IR spectra of the acrylated and methacrylated epoxy resins of sesame seed oil were identified at 2710 and $3002 \mathrm{~cm}^{-1}$ respectively. This ascertained the functionalization of the acids used for modification and clearly demonstrates the potential of sesame seed oil for biobased resin synthesis.
\end{abstract}

Keywords: epoxidation, acrylation, methacrylation, sesame seed oil

\section{INTRODUCTION}

Recent interest in the use of renewable resources has motivated researchers to develop biodegradable resin due to environmental concerns and high cost posed by petrochemical based resins. (Aleksandar, 2014; Belgacem \& Gandini, 2008; Kong et al., 2013; Lopes et al., 2013; Moseiwick et al., 2013; Siyanbola et al., 2013).

Currently the synthesis of biobased polymeric resins from readily available, sustainable, eco-firendly vegetable seeds has paved way for its utilization as functional based material for the production of resins (Blavo et al., 2001; Campanella et al., 2004; Xia \& Larock, 2010).

Plant oils are being considered as important renewable raw materials for the production of bio-based polymer materials due to the unsaturated fatty triglycerides it contains (Leveneur, 2017; Nikesh et al., 2015; Rakotonirainy \& Padua, 2001). These unsaturated $\mathrm{C}=\mathrm{C}$ present in the oil can be modified into reactive group via epoxidation (Chen et al., 2019) hence this has been actualized by various researchers.

Sinadovic-Fiser et al. (2001) have studied the kinetics of the epoxidation of soybean oil in bulk by peracetic acid formed in situ, in the presence of an ion exchange resin as the catalyst, the kinetic model proposed was validated, and the optimal conditions for obtaining $91 \%$ conversion, $5.99 \%$ epoxide content in product were found to be 0.5 mole of glacial acetic acid and $1.1 \mathrm{~mol}$ of hydrogen peroxide per mole of ethylenic unsaturation at $75^{\circ} \mathrm{C}$, over the reaction time of 8 hours.

Goud et al. (2007) worked on the kinetics of epoxidation of Jatropha oil using peroxyacetic/peroxyformic acid in the presence of an acidic ion exchange resin as catalyst in or without toluene. The kinetic model proposed was validated and the activation energy for the epoxidation was found to be $53.6 \mathrm{KJ} / \mathrm{mol}$.

The kinetics of the epoxidation of rubber seed oil was investigated by Okiemen et al. (2002), hence there was a good fitting between experimental and the actual data, which indicates that the oil was suitably epoxidised.

Epoxidized vegetable oil not only improves the stability of oils, but also provides adequate reactivity to form chemical linkages with other polymer chains (Cai et al., 2008; Campanella et al., 2004), hence the need to further modify epoxidised oil via acrylation, methacrylation or hydroxylation to produce various range of thermosets. These thermosets present improved physical properties such as higher flexibility, adhesion and resistance to water and chemicals (Xia \& Larock, 2010). Nwosu-Obieogu et al. (2017) developed biobased polymeric resins from modified linseed and sunflower oil, the FTIR analysis showed that the oils were suitably modified.

Sesame seed (Sesamum Indicum L.) a member of the family Pedaliaceae is among the earliest crops processed for oil production. (Anilakumar et al., 2010; Hassan, 2012), it is grown in Asia and Africa, applied in medicine, pharmaceuticals and nutrition. It is very rich in unsaturated fatty triglycerides (Crews et al., 2006), not good for frying due to its decomposition at low 
temperature, hence the need to utilize it effectively through conversion to biobased resins and biofuels. (Bang et al., 2014; Musik \& Milchert, 2017; Saydut et al., 2008).

Gharby et al. (2015) characterized the chemical and nutritional constituents of sesame seed oil grown in Morrocco, the results revealed a high degree of unsaturation with linoleic acid (46.9\%) followed by oleic acid (37.4\%), which is an indication that it can be functionalized.

Music et al. (2018) compared epoxidation of sesame oil with performic acid and peracetic acid, performic acid gave a higher epoxy number than peracetic acid, hence this work tends to add value to sesame seed oil by epoxidation and further modification via acrylation and methacrylation of the epoxidised oil.

\section{MATERIALS AND METHODS}

Materials used in this work include Sesame Seed (2.5kg), purchased from Mgbowo market, Enugu state, Nigeria; $\mathrm{H}_{2} \mathrm{O}_{2}(30$ wt $\%$ ), obtained from Chemical Engineering Analysis Laboratory, MOUAU, Abia State, Nigeria; Acetic acid (95\%), Acrylic Acid (94\%), Methacrylic Acid (99\%), hydroquinone powder (99\%), used as a free radical inhibitor, Sodium Carbonate, oven, grinder, mortar and pestle, muslin cloth, three necked round bottom flask, oil bath, thermometer, electronic weighing balance, condenser, heater, separation funnel, $250 \mathrm{ml}$ beakers, test tubes, stirring rods, retort stand and watch.

\section{Epoxidation Procedure}

The sesame oil was extracted using mechanical expression from its seed. The epoxidation method reported by Goud et al. (2007) was adopted in this work with little variation in procedure. Sesame oil $(60 \mathrm{~g})$ was placed in the flask, $4.3 \mathrm{~g}$ of acetic acid was added to the flask after about five minutes, and the mixture was stirred continuously for $30 \mathrm{mins}$. Then $29.89 \mathrm{~g}$ of $30 \mathrm{wt} \%$ aqueous hydrogen peroxide was added drop wise to the reaction mixture, as oxygen donor, at a rate such that the hydrogen peroxide addition was completed within half an hour; considering the completion of hydrogen peroxide addition as zero time. The mole ratio of the components used was 1:1.5:0.5. After the complete addition of hydrogen peroxide, the mixture was heated under reflux at the same desired temperature of $75^{\circ} \mathrm{C}$ and with rapid stirring. The rapid stirring of $200 \mathrm{rpm}$ was maintained throughout the experiment to achieve uniform dispersion of oil and to avoid zones of high peroxide concentration that could lead to explosion. The reaction setup was repeated for 5, 6 and 7 hours after the first 4 hour setup. The collected samples (ESO) were then immediately washed with sodium carbonate dissolved in distilled water to remove free acids and other unreacted components. $20 \mathrm{~g}$ of $\mathrm{Na}_{2} \mathrm{CO}_{3}$ was first dissolved in $100 \mathrm{ml}$ of distilled water. Then, another $100 \mathrm{ml}$ of distilled water was further added to the mixture. The total mixture was separated using a separation funnel.

\section{Analytical Techniques}

\section{lodine value}

The iodine value of the oil sample was determined by the Wiji's method of the Association of Oil Chemists. $0.5 \mathrm{~g}$ of the sample was poured in a conical flask. $10 \mathrm{ml}$ of carbon tetrachloride was added to the oil and was shaken to allow the oil dissolve. Also 20 $\mathrm{ml}$ of Wiji's iodine solution was later added to the mixture. It was stirred vigorously, stoppered and kept in the dark for 30 minutes. Subsequently, $15 \mathrm{ml}$ of potassium iodide solution followed by $100 \mathrm{ml}$ of distilled water was added. The mixture was titrated against $0.01 \mathrm{~N}$ sodium thiosulphate solution. A reagent black was also titrated as well.

lodine value of epoxidized samples was calculated after analysis using the formula:

$$
I V=\frac{(B-S) \times M \times 12.69}{W}
$$

Where:

$$
\begin{aligned}
\text { IV } & =\text { lodine value of samples } \\
S & =\text { Volume of } \mathrm{Na}_{2} \mathrm{~S}_{2} \mathrm{O}_{3} \text { used for sample }(\mathrm{ml}), \\
B & =\text { Volume of } \mathrm{Na}_{2} \mathrm{~S}_{2} \mathrm{O}_{3} \text { used for blank }(\mathrm{ml}), \\
W & =\text { Weight of sample used }(\mathrm{g}), \\
M & =\text { Molarity of the } \mathrm{Na}_{2} \mathrm{~S}_{2} \mathrm{O}_{3} \text { used. }
\end{aligned}
$$

Conversion was calculated with the formula below:

$$
C_{G O}=\frac{I V_{o}-I V}{I V_{o}} \times 100
$$

Where:

$$
\begin{aligned}
& I V_{0}=\text { lodine value before treatment } \\
& I V=\text { lodine value after treatment }
\end{aligned}
$$

\section{Oxirane Oxygen content}

The percentage of the oxirane oxygen was determined by direct method established by using hydrobromic acid solution in glacial acetic acid. The content oxirane oxygen (0O) was calculated according to the consumed amount of the halogen atom (Swern et al., 1947). 
Table 1. The percentage of iodine value of the epoxidized sesame oil at different time intervals

\begin{tabular}{ccc}
\hline Time (hr) & lodine value (\%) \\
\hline 4 & 27.14 \\
\hline 5 & 39.99 \\
\hline 6 & 65.26 \\
\hline 7 & 76.54 \\
\hline
\end{tabular}

Table 2. The percentage of oxirane oxygen content of epoxidized sesame oil at different time intervals

\begin{tabular}{ccc}
\hline Time (hr) & Oxirane value (\%) \\
\hline 4 & 1.38 \\
\hline 5 & 1.51 \\
\hline 6 & 2.43 & 3.83 \\
\hline 7 & & \\
\hline
\end{tabular}

The Oxirane Oxygen Content of the analyzed samples was calculated using the formula:

Where:

$$
O V=\frac{(B-S) \times M \times A_{o} \times 100}{1000 W}
$$

$$
\begin{aligned}
\mathrm{S} & =\text { Volume of } \mathrm{NaOH} \text { used for sample }(\mathrm{ml}) \\
\mathrm{B} & =\text { Volume of } \mathrm{NaOH} \text { used for blank }(\mathrm{ml}) \\
\mathrm{M} & =\text { Molarity of the } \mathrm{NaOH} \text { used } \\
\mathrm{W} & =\text { Weight of sample used }(\mathrm{g}) \\
A_{0} & =\text { Atomic weight of oxygen }
\end{aligned}
$$

\section{Synthesis of Acrylated Sesame Seed Oil}

The epoxidized sesame seed oil ( $30.0 \mathrm{~g})$ was heated at a room temperature while acrylic acid $(9.79 \mathrm{~g})$ containing hydroquinone $(0.02 \mathrm{~g}, 0.25 \mathrm{wt} \%)$ was added at 30 minutes. The reaction mixture was heated under reflux for 6 hours at $90^{\circ} \mathrm{C}$ with constant stirring. The mixture was then cooled to room temperature. The obtained product, Acrylated Epoxidized Sesame Oil (AESO) was washed with distilled water and then isolated.

\section{Synthesis of Methacrylated Sesame Seed Oil}

The epoxidized sesame oil ( $30.0 \mathrm{~g})$ was heated at a room temperature while methacrylic acid $(9.79 \mathrm{~g})$ containing hydroquinone $(0.02 \mathrm{~g})$ was added at 30 minutes of the experiment. The reaction mixture was heated under reflux for 6 hours at $90^{\circ} \mathrm{C}$ with constant stirring. The mixture was then cooled to room temperature and washed with distilled water. The obtained product, Methacrylated Epoxidized Sesame Oil (MESO) was isolated.

\section{FT-IR Analysis}

FT-IR spectroscopy analysis was employed using Nicolet iS50 model to identify the various samples of pure, epoxidised and acrylated and methacrylated epoxidised sesame seed oils.

\section{RESULTS AND DISCUSSION}

The result indicated that the percentage conversion of iodine value and oxirane value in the epoxidized sesame oil increased with reaction time, hence maximum conversion of 76.54 (with iodine value of $24.68 \mathrm{gl}_{2} / 100$ goil) in Table 1 as well as $3.83 \%$ for oxirane value in Table 2 was achieved at 7hours reaction time which is in agreement with the findings of (Goud et al., 2007). From the FT-IR spectra shown in Figures 1-4, it is observed that at the wave number 3890,700 the pure sesame oil tends to form a hydroxyl group with an unsaturated carbon-carbon bond in Figure 1. The epoxidized sesame oil became saturated and formed an epoxy group at wave number of 1120 in Figure 2. The acrylated and methacrylated epoxy resins of sesame oil were obtained at the wave number of 2710 and 3002 respectively to form the acrylic and methacrylic groups in Figures 3 and 4 respectively, which is a pointer to the fact that sesame seed oil has been modified. 


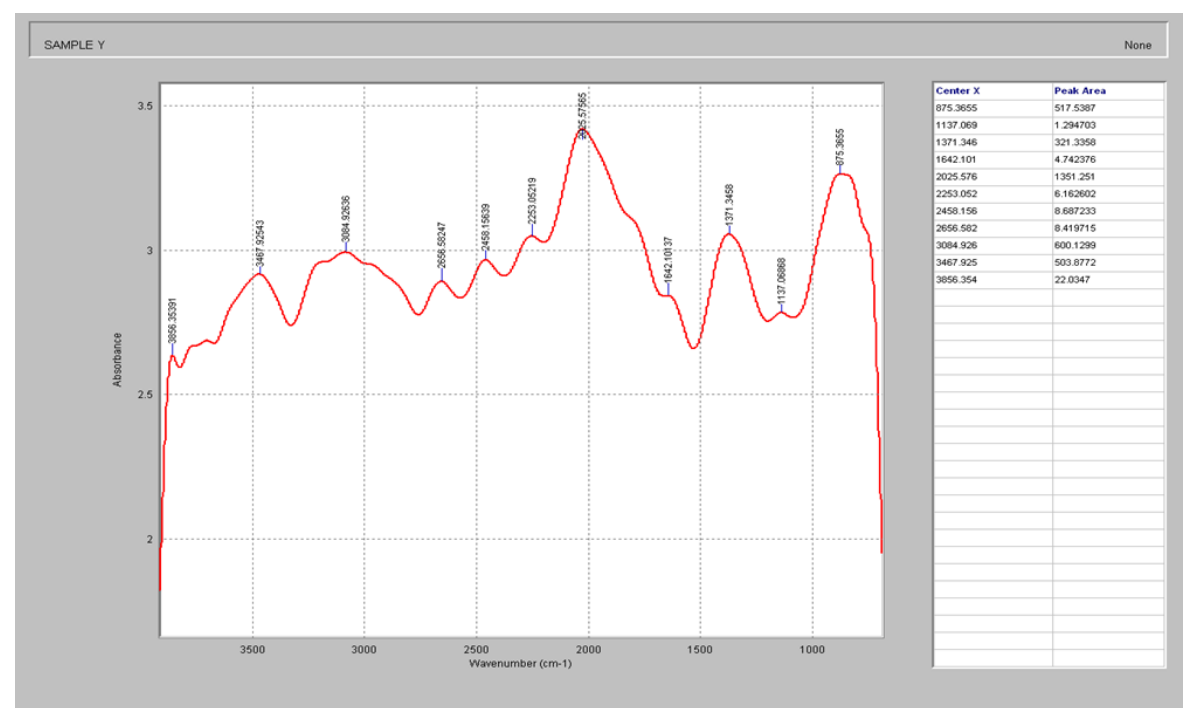

Figure 1. FT-IR of pure sesame seed oil

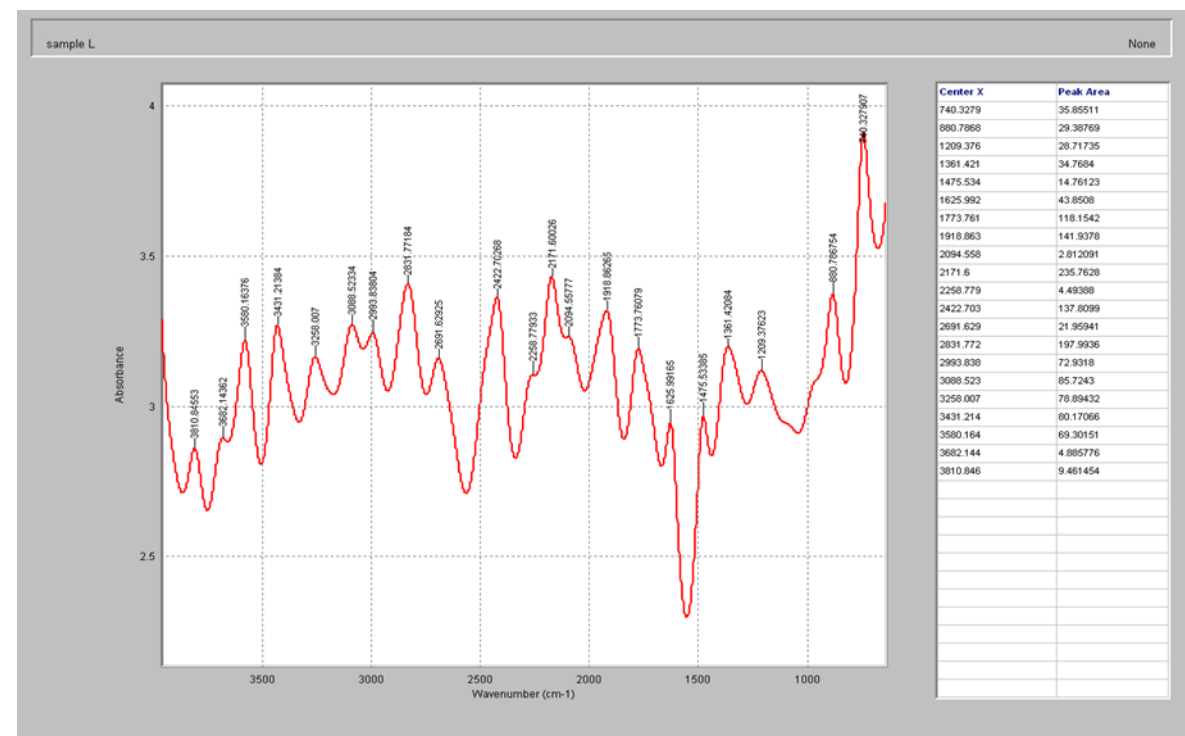

Figure 2. FT-IR of epoxidised sesame seed oil

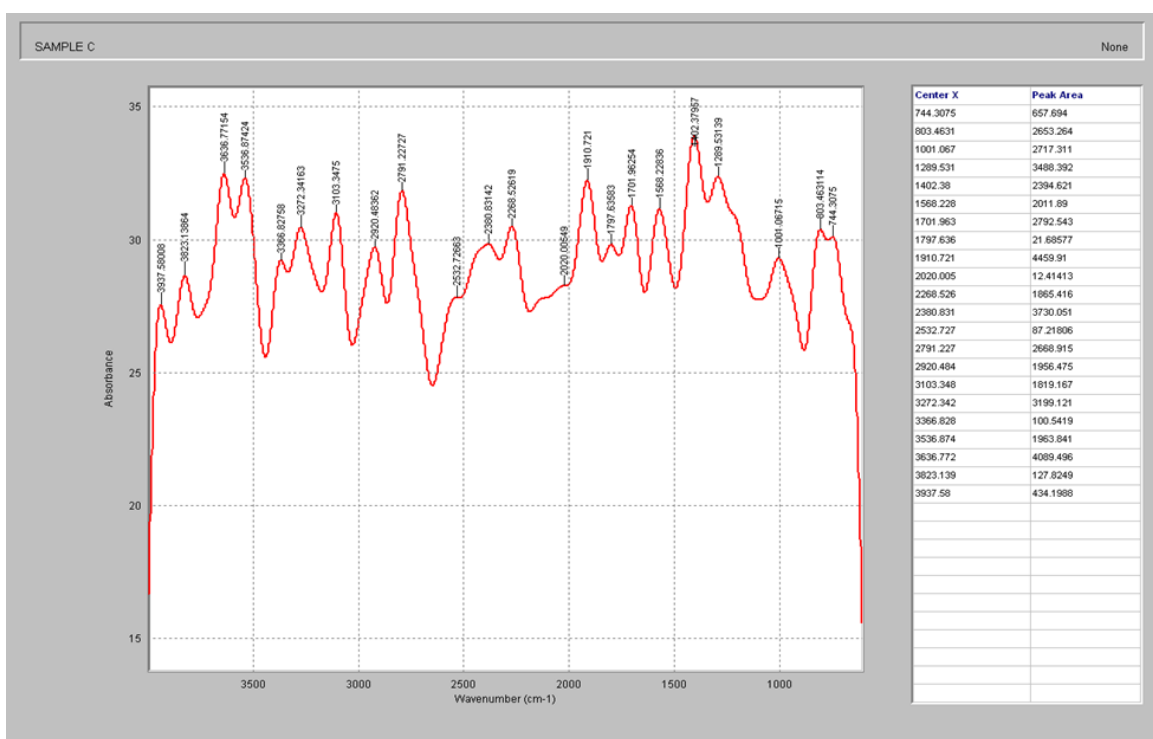

Figure 3. FTIR of acrylated sesame seed oil 


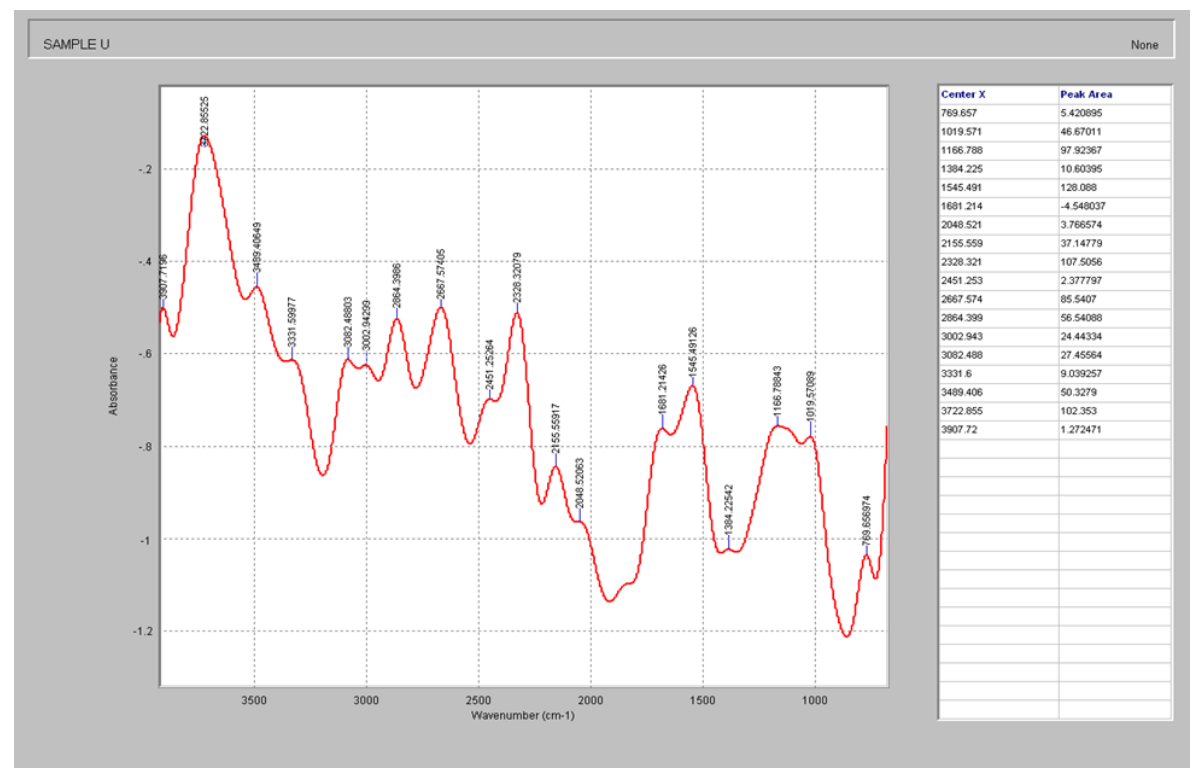

Figure 4. FTIR of methacrylated sesame seed oil

\section{CONCLUSION}

Increase in the concern about environmental pollution from petrochemical-derived polymer products, has made plant seed oil a potential replacement. From the results obtained in this work, It was found that sesame seed oil is a good starting material for oil epoxy synthesis and further modification via acrylation and methacrylation to produce biobased resin. Hence the information is for possible utilisation and application of sesame seed oils for the synthesis of bioresins and composites preparation.

\section{REFERENCES}

Aleksandar, Z. (2014). Fatty acids in vegetable oils and their importance in cosmetic industry, CHEMIK, 68(2), 103-110.

Anilkumar, K. R., Pal, A., Khanum, F., \& Bawa, A. S. (2010). Nutritional medicinal and industrial uses of sesame (Sesamum indicum L.) seeds- an overview. Agric. Conspec. Sci., 75(4) 67-70.

Bang. H. J., Kim, C. T., \& Kim, B. H. (2014). Liquid and gas chromatographic analyses of triacylglycerols for Asian sesame oil traceability. Eur. J. Lipid Sci. Technol, 116, 1354-1362. https://doi.org/10.1002/ejlt.201400089

Belgacem, M. N., \& Gandini, A. (2008). Materials from Vegetable oils: major sources, properties and applications. Monomers, polymers and composites from renewable resources, 3, 39-66. https://doi.org/10.1016/B978-0-08-045316-3.00003-X

Bhabhe, M. D., \& Athawale, V. D. (1997). Chemoenzymatic synthesis of oil-modified acrylic monomers as reactive diluents for high solids coatings. Progress in Organic Coatings, 30, 207-211. https://doi.org/10.1016/S0300-9440(96)00671-6

Blayo, A., Gandini, A., \& Le Nest, J. F. (2001). Chemical and Rheological Characterizations of Some Vegetable Oil Derivatives Commonly Used in Printing Inks. Industrial Crops and Products, 14(2), 155-167. https://doi.org/10.1016/S0926-6690(01)000796

Cai, C. S., Dai, H. G., Chen, R. S., Su, C. X., Xu, X. Y., \& Zhang, S. (2008). Studies on the kinetics of insitu epoxidation of vegetable oils. European journal of lipids science and technology, 110(4), 341-346. https://doi.org/10.1002/ejlt.200700104

Campanella, A., Baltanas, M. A., Capel-Sanchez, M. C., Campos-Martin, J. M., \& Fierro, J. L. G. (2004). Soybean oil epoxidation with hydrogen peroxide using an amorphous Ti/SiO2 catalyst. Green Chemistry, 6(7), 330-334. https://doi.org/10.1039/B404975F

Chen, J., Liu, Z., ang, K., Huang, J., Li, K., Nie, K., \& Jiang, J. (2019). Epoxidised castor oil-based diglycidyl-phthalate plasticizer: synthesis and thermal stabilizing effects on poly(vinyl chloride). Journal of Applied Polymer Science, 136(9), 471-472. https://doi.org/10.1002/app.47142

Crews, C., Hough, P., Godward, J., Brereton, P., Lees, M., Guiet, S., \& Winkelmann, W. (2006). Quantitation of the main constituents of some authentic grape seed oils of different origin. J. Agric. Food Chem. 54, 6261-6265.

Gharby, S., Harhar, H., Guillaume, D., Roudani, A., Boulbaroud, S., Ibrahimi, M., ... Charrouf, Z. (2015). Chemical investigation of Nigella sativa L. seed oil produced in Morocco, J. Saudi Sco. Agric. Sci., 14(2) $172-177$. https://doi.org/10.1016/j.jssas.2013.12.001

Goud, V. V., Patwardhan, A. V., Dinda, S., \& Pradhan, N. C. (2007) Kinetics of epoxidation of jatropha oil with peroxyacetic and peroxyformic acid catalysed by acidic ion exchange resin. Chem Eng Sci, 62(15), 4065 _76. https://doi.org/10.1016/j.ces.2007.04.038 
Hassan, M. A. M. (2012). Studies on Egyptian sesame seeds (sesamum indicum L.) and its products. I- physicochemical analysis and phenolic acids of roasted Egyptian sesame seeds (Sesamum indicum L.). World J. Dairy Food Sci., 7(2), 195-201.

Kong, X., Liu, G., Qi, H., \& Curtis, J. M. (2013). Preparation and characterization of high solid polyurethane coating systems based on vegetable oil derive polyols. Prog. Org. Coat., 76, 1151-1160. https://doi.org/10.1016/j.porgcoat.2013.03.019

Leveneur, S. (2017). Thermal safety assessment through the concept of structure reactivity; application to vegetable oil valorization. Org. Process Res. Dev., 21(4) 543-550. https://doi.org/10.1021/acs.oprd.6b00405

Lopes, R. V. V., Loureiro, N. P. D., Pezzin, A. P. T., Gomes, A. C. M., Resick, I. S., \& Sales, M. J. A. (2013). Synthesis of polyols and polyurethanes from vegetable oils-kinetic and characterization. J. Polym. Res., 20, 1-9. https://doi.org/10.1007/s10965-0130238-x

Mosiewick, M. A., \& Araguren, M. I. A. (2013). Short review on novel biocomposites based on plant oil precursor. Europ. Polym. J., 49, 1243-1256. https://doi.org/10.1016/j.eurpolymj.2013.02.034

Musik, M., \& Milchert, E. (2017). Selective epoxidation of sesame oil with peracetic acid. Molecular catalysis, 433, $170-174$. https://doi.org/10.1016/j.mcat.2017.02.012

Musik, M., Milchert E., \& Malarczyk-Matusiak, K. (2018). Technological parameters of epoxidation of sesame oil with performic acid. Polish Journal of Chemical Technology, 20(3), 53-59. https://doi.org/10.2478/pjct-2018-0038

Nikesh, B., Samarth, N., \& Mahanwar, P. (2015). Modified vegetable oil based additive as a future polymeric material-review. Open journal of organic polymer materials, 5, 1-22. https://doi.org/10.4236/ojopm.2015.51001

Nwosu-Obieogu, K., Aguele, F. O., \& Chiemenem, L. I. (2017). Production of biobased polymerix resins from modified linseed oil and sunflower oil. Umudike Journal of Engineering and Technology, (UJET), 3(2) 39-44.

Okieimen, F. E., Bakare, O. I., \& Okieimen, C. O. (2002). Studies on the epoxidation of rubber seed oil. Industrial Crops and Products, 15, 139-144. https://doi.org/10.1016/S0926-6690(01)00104-2

Rakotonirainy, A. M., \& Padua, G. (2001). Effects of lamination and coating with drying oils on tensile and barrier properties of zein films. Journal of Agricultural and Food Chemistry, 49, 2860-2863. https://doi.org/10.1021/jf000845u

Saydut, A., Duz, M. Z., Kaya, C., Kadafar, A. B., \& Hamamci, C. (2008). Transesterified sesame (Sesamum indicum L.) seed oil as a biodiesel fuel. Bioresour. Technol., 99, 6656-6660. https://doi.org/10.1016/j.biortech.2007.11.063

Siyanbola, T. O., Sasidhar, K., Anjaneyulu, B., Kumar, K. P., Rao, B. V. S. K., Rananuj, N., ... Raju, K. V. S. N. (2013). Anti-microbial and anti-corrosive poly(ester amide urethane) siloxane modified $\mathrm{ZnO}$ hybrid coatings from Thevetia peruviana seed oil. Journal of Material Science, 48(23), 8215-8227. https://doi.org/10.1007/s10853-013-7633-x

Snezana, S.-F., Milovan, J., \& Zoran, S. (2001). Kinetics of in situ epoxidation of Soyabean oil in bulk catalyzed by ion exchange resin. Kansas polymer research.

Swern, D., Findley, T. W., Billen, G. N., \& Scalan, J. T. (1947). Determination of Oxirane Oxygen. Anal Chem, 19, 414-415. https://doi.org/10.1021/ac60006a018

Xia, Y., \& Larock, R. C. (2010). Vegetable oil-based polymeric materials: synthesis, properties and applications. Green chemistry, 12(11), 1893-1909. https://doi.org/10.1039/c0gc00264j 